\title{
Atypical Presentation of Cervical Pott's Disease: A Case Report
}

\author{
Emecheta G. Okwudire ${ }^{*}$, Ugonna M. Ezenwugo ${ }^{2}$, Johnpatrick U. Ugwoegbu ${ }^{2}$, \\ Chika A. Okoro ${ }^{3}$, Ifeanyichukwu Isiozor ${ }^{2}$ \\ ${ }^{1}$ Department of Radiology, NSIA Umuahia Diagnostic Centre, Umuahia, Abia State, Nigeria \\ ${ }^{2}$ Department of Radiology, Federal Medical Centre, Owerri, Imo State, Nigeria \\ ${ }^{3}$ Universal Health Coverage, Communicable Diseases Cluster, World Health Organization Office, Owerri, Imo State, Nigeria \\ Email: *meetle1@gmail.com
}

How to cite this paper: Okwudire, E.G. Ezenwugo, U.M., Ugwoegbu, J.U., Okoro, C.A. and Isiozor, I. (2021) Atypical Presentation of Cervical Pott's Disease: A Case Report. Journal of Tuberculosis Research, $\mathbf{9}$, 211-218.

https://doi.org/10.4236/jtr.2021.93020

Received: July 29, 2021

Accepted: September 20, 2021

Published: September 23, 2021

Copyright (c) 2021 by author(s) and Scientific Research Publishing Inc. This work is licensed under the Creative Commons Attribution International License (CC BY 4.0).

http://creativecommons.org/licenses/by/4.0/

\begin{abstract}
Tuberculous spondylitis, also known as Pott's disease, is due to infection of the spine by mycobacterium tuberculosis (MTB) leading to vertebral body and inter-vertebral disc destruction. It is the most common form of musculoskeletal tuberculosis most frequently affecting the thoracolumbar spine and is commoner in young people. Onset of this condition is insidious and its clinical presentation is non specific. However, Pott's disease may be complicated by neurologic deficits including paraplegia or even quadriplegia, with huge health, economic and psychological burden. Following is a case report of Pott's disease involving the cervical spine in a 33-year old farmer presenting unusually with paraplegia and a negative Mantoux test. It is reported because this very uncommon condition is highly treatable, and there is need for a raised index of suspicion in order to diagnose this condition early, thus limiting its complications. The role of MRI in diagnosis of Pott's disease is also highlighted.
\end{abstract}

\section{Keywords}

Tuberculosis, Pott's Disease, Spine, MRI, Hemiplegia

\section{Introduction}

Pott's disease, also known as tuberculous spondylitis, refers to vertebral body and inter-vertebral disc destruction by Mycobacterium tuberculosis (MTB) [1].

Pott's disease accounts for about $1 \%-2 \%$ of all cases of TB [1]. It is the most common and most dangerous form of musculoskeletal TB accounting for about $50 \%$ of cases [2]. The lower thoracic and upper lumbar levels of the spine are most commonly affected, with cervical Pott's occurring in about $10 \%$ of cases 
[1]. There is no sex predilection. The peak age of onset is in the first two decades of life [3].

Patients usually present with back pain, lower limb weakness/paraplegia and kyphotic deformity. Constitutional symptoms (fever and weight loss) are also common. The onset of these symptoms is usually insidious with slow progression [1].

Pott's disease is due to haematogenous or lymphatic spread of mycobacterium tuberculosis to the spine usually from clinically silent respiratory or urogenital tract infection [2]. Spread to the vertebral body may also be from contiguous para-aortic nodes. There is usually a slow collapse of one or usually more vertebral bodies, resulting in gibbus deformity [1]. This angulation, coupled with epidural granulation tissue and bony fragments, can lead to cord compression. In late-stage spinal TB, large paraspinal 'cold' abscesses are common.

Neurologic complication is the most dreaded and crippling aspect of spinal tuberculosis and occurs mainly due to late diagnosis and treatment [4].

This case is reported to raise awareness that, though cervical Pott's disease is uncommon, it should always be considered during examination and to highlight the role of MRI in diagnosis.

\section{Case Report}

Mr O.K, a 33-year-old poultry farmer presented to the hospital with a 6 month history of upper back and chest pain, and 3 day history of weakness and inability to move both lower limbs. Pain was gradual in onset, dull and non-radiating. It gradually progressed, making it difficult for him to turn his neck. There was no history of trauma, chronic cough, fever or weight loss. Pain was relieved by analgesics which he routinely purchased at a chemist shop. A few days prior to presentation, he noticed pricking sensation in both lower limbs which he attributed to the drug side effects. However, the following morning he was unable to stand without support and became unable to move both feet within hours. There was no associated incontinence. Patient was single, drank alcohol occasionally and did not smoke. He was a graduate of Animal Production and Health who lived alone in a rented apartment. He had no significant past medical and surgical history.

General examination revealed a young man, not pale or febrile. Neurological examination revealed moderate cervical tenderness with no gibbus deformity or soft tissue swelling. Power was two (2/5) in both lower limbs with reduction in tone. There was hyper-reflexia on knee jerk. Sensation was intact. Power, tone and reflexes were normal in both upper limbs. Systemic examination of the chest, and abdomen revealed no abnormalities.

A diagnosis of dorsal cord compression syndrome? Secondary to tuberculosis of spine was made. Laboratory as well as radiologic investigations was then requested. Full blood count was done, which showed haemoglobin of $12 \mathrm{~g} / \mathrm{dl}$ and total white blood cells (WBC) count of 6000. Erythrocyte sedimentation rate (ESR) 
was $5 \mathrm{~mm}$ in the first hour. A Mantoux test was negative $(4 \mathrm{~mm})$. Retroviral screen was also negative. Serum electrolyte, Urea, and Creatinine as well as fasting blood glucose levels were within normal limits.

Initial thoracic radiographs (Figure 1) showed normal dorsal curvature and vertebral alignment with vertebral bodies normal in height. Posterior elements and disc spaces were also normal. The chest radiograph and abdominal ultrasound done were within normal limits. An MRI was recommended to exclude spinal cord lesion. The lumbar and lower dorsal spine was normal on MRI. However, some signal abnormalities were noticed in upper thoracic vertebra and the examination extended superiorly to include the entire cervical spine. The cervical spine was straightened and showed destruction of C7 to T4 vertebrae worse at T1 and T2 with retropulsion and spinal compression (Figure 2). An epidural collection hyperintense on $\mathrm{T} 2 \mathrm{~W}$ with peripheral contrast enhancement extending from C7 to T3 further compressed the cord causing signal changes and mild expansion at this level (Figure 2 and Figure 3). There were extensive para-vertebral and pre-vertebral collections of similar signal characteristics elevating the anterior longitudinal ligament from C5 to T3 (Figure 2) which extended into the apex of the chest on the right (Figure 4). A diagnosis of multiple contiguous vertebral destruction with extra-spinal and intra-spinal collections and spinal cord compression due to Pott's disease was made. The collection in the root of the neck was surgically evacuated and yielded thick, cheesy material. Ziehl-Neelsen

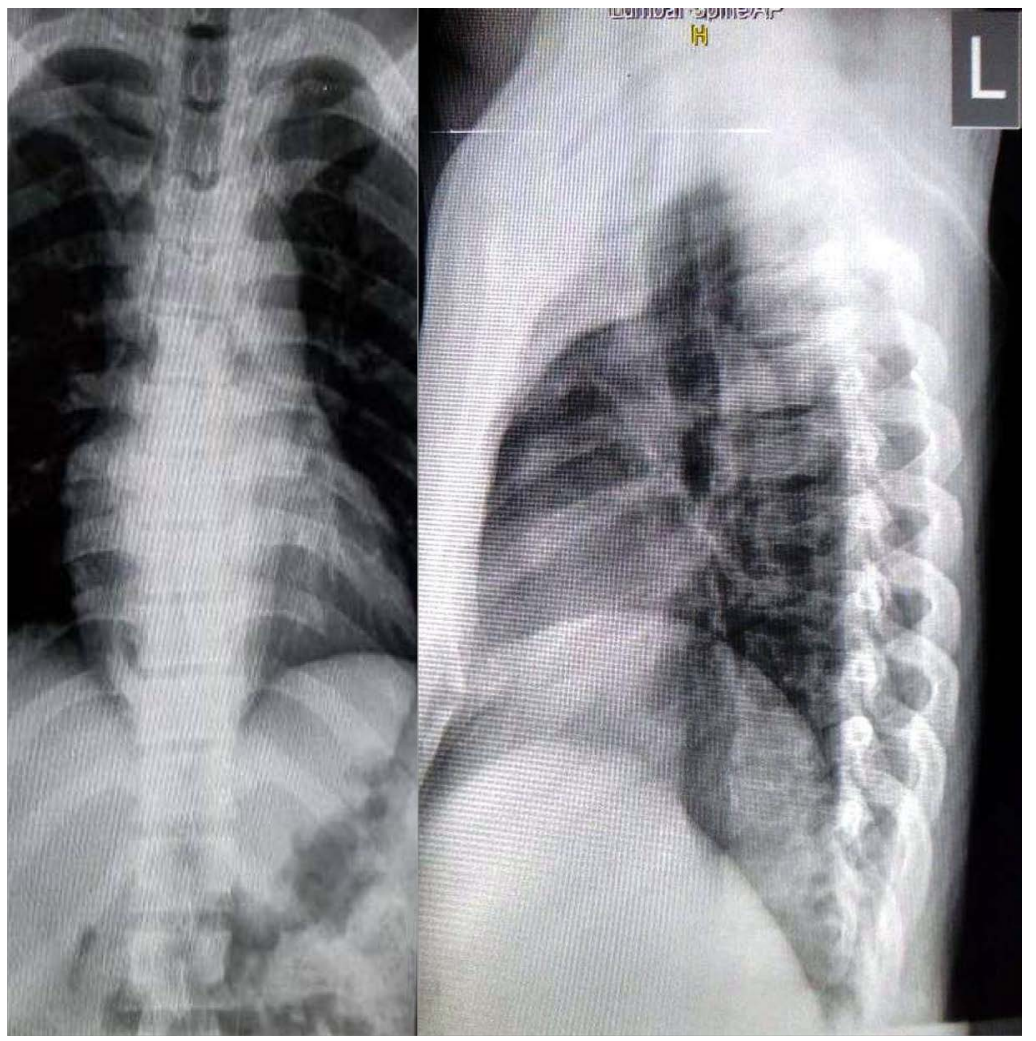

Figure 1. AP and Lateral radiographs of the thoracic spine showing normal curvature and inter-vertebral alignment and posterior elements. No para-vertebral masses seen. 


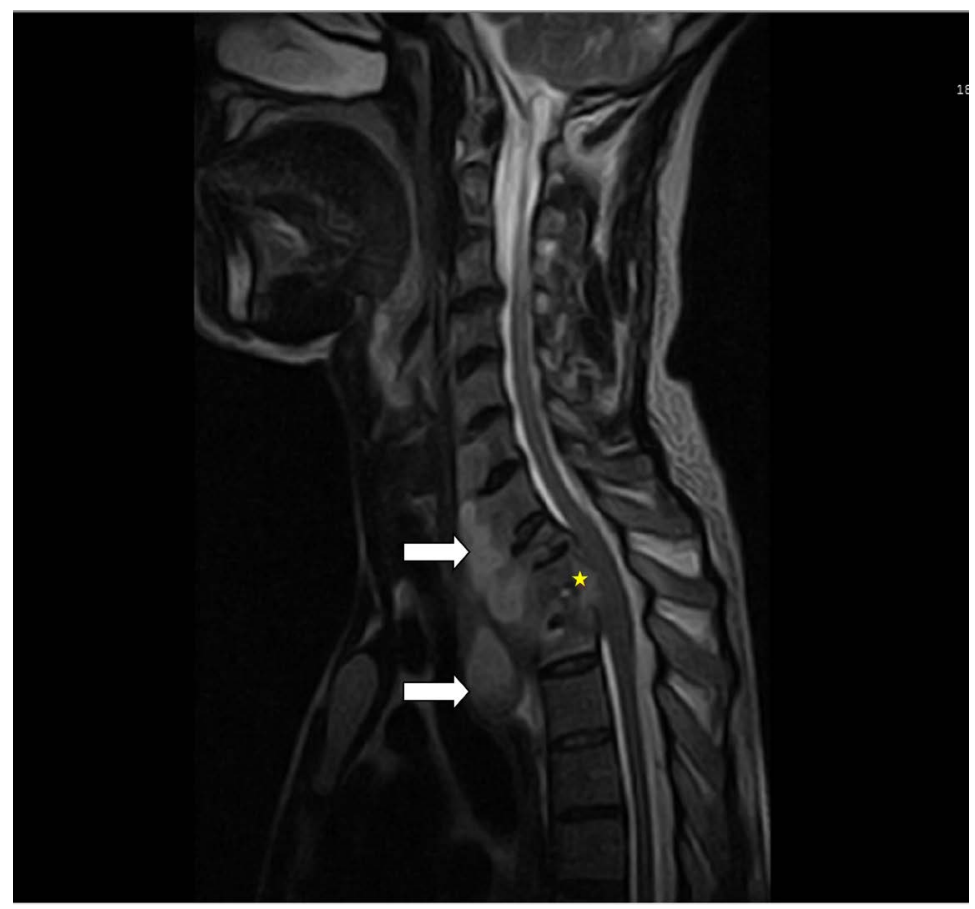

Figure 2. Sagittal T2W cervical MRI showing contiguous destruction of C7 to T2 vertebra and intervening discs with extensive loculated para-vertebral and pre-vertebral collections (arrows). An epidural collection ${ }^{*}$ ) hyperintense on T2W is noted to mildly compress the spinal cord causing signal changes and mild expansion at this level.

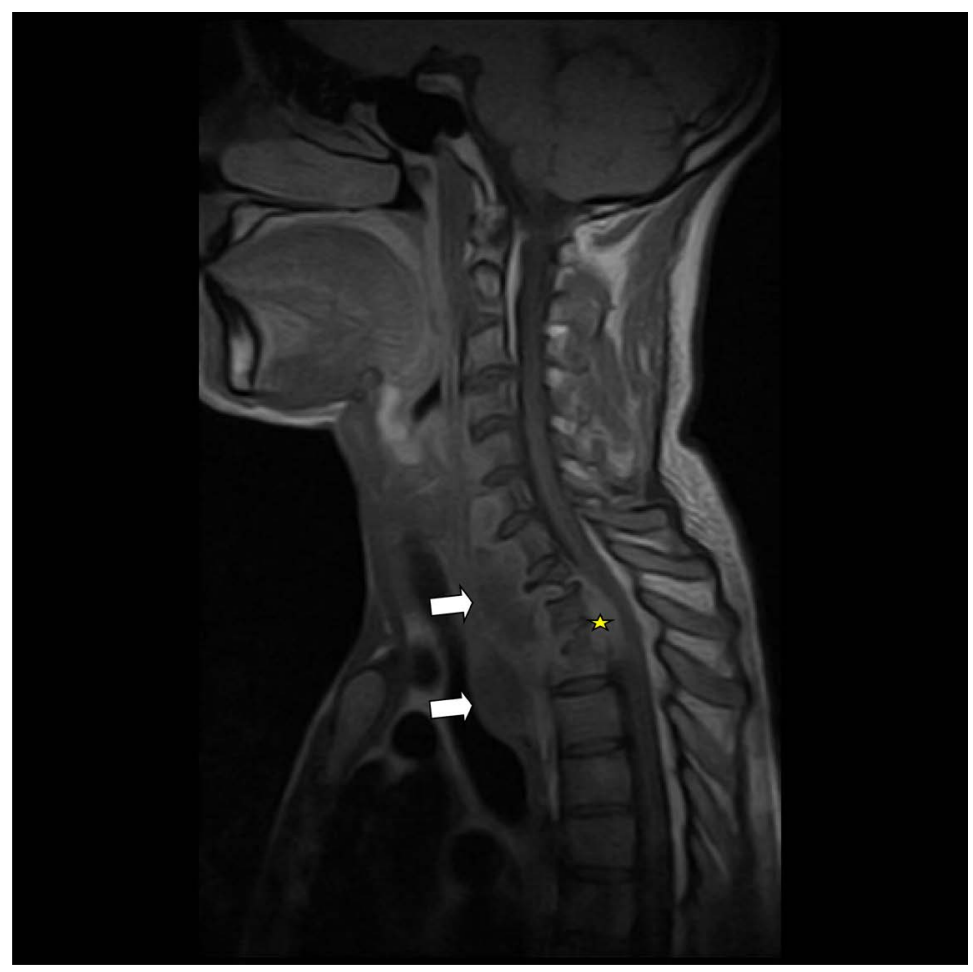

Figure 3. Contrast-enhanced sagittal T1W cervical MRI showing contiguous destruction of C7 to T2 vertebra and some intervening discs with extensive ring-enhancing loculated para-vertebral (arrows) and pre-vertebral collections. The spinal cord compression by epidural enhancing collections $(\mathcal{3})$ is better demonstrated 


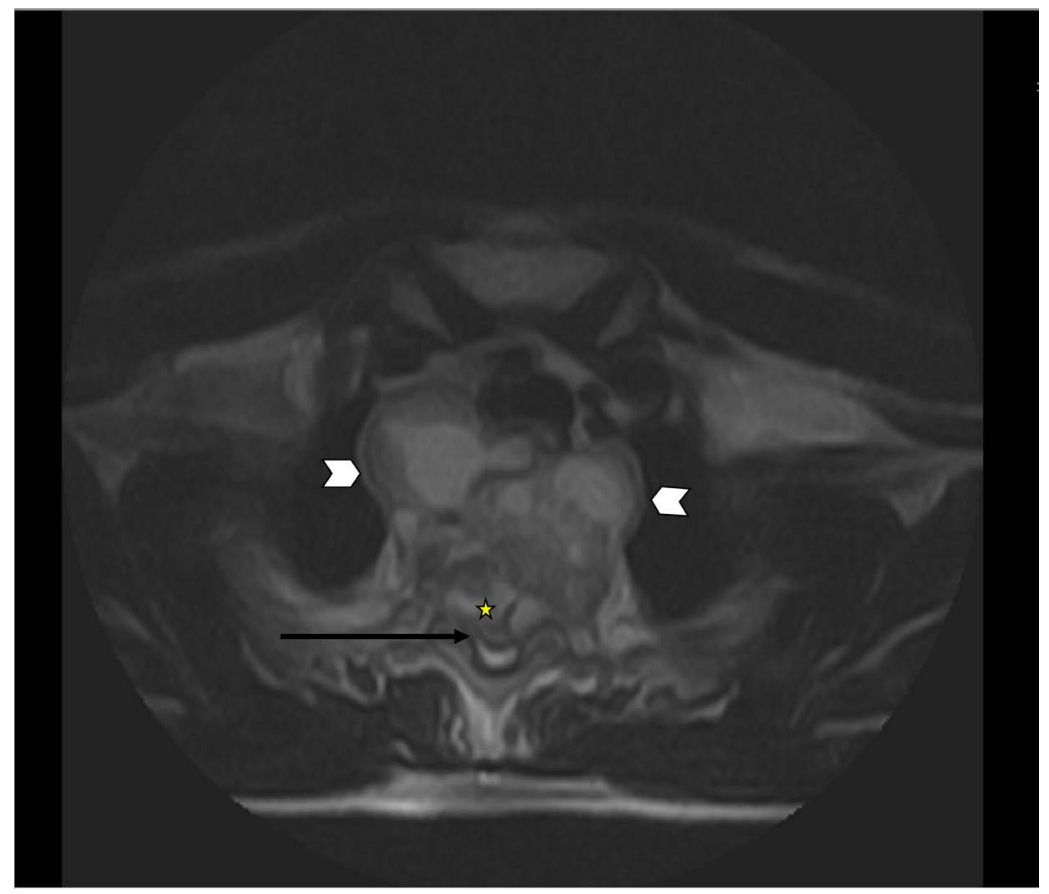

Figure 4. Axial T2W cervical MRI at the apex of the lungs showing complete vertebral body destruction with extensive thick-walled loculated pre-vertebral and para-vertebral hyperintense collections (arrowheads). An anterior epidural $\left(^{*}\right)$ collection is also seen compressing the spinal cord (black arrow).

stain of the aspirate showed acid fast bacilli and a definitive diagnosis of Pott's disease of the cervico-thoracic junction was established.

Patient was commenced on first line anti-Kochs therapy (Rifampicin, Isoniazid, Pyrazinamide, and Ethambutol) as well as Dexamethasone tablets for two month and then Isoniazid and Rifampicin for a further 10 months. On follow-up a month later, he had made a remarkable recovery with power of $4 / 5$ in both limbs and was able to stand without support. At his 6-month visit, patient had fully recovered motor function and remained so a year after surgery when he was finally discharged.

\section{Discussion and Conclusion}

Tuberculosis (TB) has existed for millennia and remains a major global health problem, ranking above HIV/AIDS as one of the leading causes of death from an infectious disease [5].

It is a common disease among developing countries and Nigeria ranks fourth among the 30 high burden countries with an estimated 10.4 million new TB cases in 2015, the majority (56\%) were among men [3]. Tuberculosis of the spine (Pott's disease, TB spondylitis) is one of the oldest neurological diseases for which clear evidence is found and was first described by Sir Percival Pott's in 1779 [6].

Pott's disease is a major cause of non-traumatic paraplegia and its attendant economic repercussion among adults in many developing countries such as $\mathrm{Ni}$ geria where pulmonary $\mathrm{TB}$ is prevalent owing to poor nutrition and environ- 
mental sanitation [7]. It accounts for about 50\% of all skeletal TB, about $15 \%$ of all cases of extra-pulmonary TB, and about $1 \%$ to $2 \%$ of all cases of TB [8]. Most reported cases of spinal $\mathrm{TB}$ are in the lower thoracic and thoraco-lumbar areas, while spinal TB in the cervical region is less common with a reported prevalence of $4 \%$ in Ile-Ife [3] [5]. The normal route of entry of $M$. tuberculosis is the respiratory tract with haematological spread. Secondary haematological seeding can occur from a silent focus elsewhere in the body, e.g. genito-urinary tract, gut, or tonsils [2]. Another mode of spread to the vertebral bodies is through the lymphatic system, usually from involved contiguous para-aortic lymph nodes [9]. Typically more than one vertebra is involved and more than one component of the spine is involved namely the vertebral body, inter-vertebral disc, the ligaments, para-vertebral soft tissues and the epidural space [1]. Damage by the tubercle bacilli starts in the cancellous bone and extends to the cortex. The inflammation slowly spreads to the vertebra via the disc space or subligamentally [1] [4]. When the disease has advanced there is progressive vertebral collapse resulting in kyphosis and gibbus formation [1] [7]. The spinal cord may become involved in compression by bony and/or expanding abscess or by direct involvement of the cord and leptomeninges by granulation tissue [10]. The index patient had involvement of all these spinal structures with cervical cord compression from epidural collection and vertebral body retropulsion.

Most cases present with pain overlying the affected vertebrae, low-grade fever, chills, weight loss and non-specific symptoms [1] [2]. Back pain and lower limb weakness have been reported as the commonest presenting features in some local studies [11]. Paraplegia or paraparesis can be the first sign of spinal disease [7]. The onset of symptoms is insidious and disease progression is typically slow in Pott's disease lasting several weeks to months and even years [8] [12]. However, Pott's disease of the cervical spine can cause rapidly progressive symptoms [7]. This was the case in our patient.

While globally, use of rapid molecular tests is increasing and many countries are phasing out use of smear microscopy for diagnostic purposes, a considerable proportion of the TB cases reported to WHO are still clinically diagnosed rather than bacteriologically confirmed [3]. The diagnosis of musculoskeletal TB thus remains a challenge to clinicians and requires a high index of suspicion and radiologic investigations remain key to diagnosis of spinal TB [13]. Radiologic films are commonly non-diagnostic and imaging studies are not fully reliable for differentiating spinal TB from other infections or neoplasms, including Staphylococcus aureus osteomylitis, brucellosis, actinomycosis, histoplasmosis, blastomycosis, multiple myeloma, and metastases. As a result of this, bacteriologic and/or histologic confirmation must be obtained [7] [14].

Plain radiography remains basic and may reveal advanced lesions with vertebral osteolysis and disc space narrowing which are similar to findings in pyogenic spondylitis. Obisesan et al. attempted a radiological classification of radiographic findings in spinal TB into seven categories [15]. This patient had normal 
chest radiograph findings making the diagnosis more challenging. Computed Tomography (CT) provides much better bony detail of irregular lytic lesions, sclerosis, disc collapse and disruption of bone circumference than plain radiographs. However CT is less accurate in defining the epidural extension of the disease and its effect on neural structures [13]. Magnetic Resonance Imaging is the imaging modality of choice in spinal TB as it clearly demonstrates the extent of soft tissue disease and its effect on the theca, cord and neural foramina [16]. Diffusion Weighted MRI and Apparent Diffusion Coefficient (ADC) mapping are also useful in differentiating Pott's disease from metastatic lesions of the vertebral body [13].

Laboratory tests include Mantoux skin test using purified protein derivative and the Erythrocyte sedimentation rate (ESR). A positive Mantoux test is present in $62 \%-100 \%$ of Pott's case and supports the diagnosis, but a negative test should not be considered as evidence for excluding TB [7]. The test may be negative in patients with active disease if the disease is disseminated or if the patient is immune compromised or suffering from exanthematous fever [17]. The index patient had a negative Mantoux test but was not immuno-compromised. The reason for this is unclear as there was also no evidence of disseminated TB but may be related to poor testing technique resulting in false negative results. ESR is also elevated in most cases of Pott's disease and falls with successful treatment. It is also a non specific test but is useful for monitoring response along with clinical resolution of symptoms. The present patient had a normal ESR at making it more unusual and could not be used for monitoring response. Fine needle aspiration biopsy of the aspirate is an accurate, safe and cost effective diagnostic tool [18].

The current treatment of Pott's disease is primarily medical with cure rates of up to $90 \%$ [3] [19]. It is treated for a duration of 12 months using a combination therapy of four drugs INH, Rifampicin, Pyrazinamide, and Ethambutol for 2 months; followed by INH and Rifampicin for 10 months. Spinal decompression surgery should be pursued only when necessary; indications include neurological sequelae, spinal instability, significant kyphosis, refractory pain, or failure of medical treatment.

\section{Conflicts of Interest}

The authors declare no conflicts of interest regarding the publication of this paper.

\section{References}

[1] Dahnert, W. (2011) Radiology Review Manual. 7th Edition, Lippincott Williams \& Wilkins, Philadelphia, 231. https://doi.org/10.1097/MNM.0b013e32834b6e3d

[2] Martini, M. and Quahes, M. (1988) Bone and Joint Tuberculosis: A Review 625 Cases. Orthopedics, 11, 861-866. https://doi.org/10.3928/0147-7447-19880601-04

[3] Akinyola, A., Adegbehingbe, O. and Ashaleye, C. (2006) Tuberculosis of the Spine in Nigeria: Has Anything Changed? The Internet Journal of Third World Medicine, 
4, 6-9. https://doi.org/10.5580/1dba

[4] Turgut, M. (2001) Spinal Tuberculosis (Pott's Disease): Its Clinical Presentation, Surgical Management, and Outcome. A Survey Study on 694 Patients. Neurosurgical Review, 24, 8-13. https://doi.org/10.1007/PL00011973

[5] WHO (2016) Global Tuberculosis Report 2016. Geneva, 5.

[6] Hidalgo, J.A. and Alangden, G. (2019) Pott Disease (Tuberculous [TB] Spondylitis). http://emedicine.medscape.com/article/226141

[7] Owolabi, L.F., Nagoda, M.M., Saaila, A.A. and Aliyu, I. (2010) Spinal TB in Adults: A Study of 87 Cases in North Western Nigeria. Neurology Asia, 15, 239-244.

[8] Fancourt, G.J., Ebden, P. and Garner, P. (1986) Bone Tuberculosis: Results and Experience in Leicestershire. British Journal of Diseases of the Chest, 80, 265-272. https://doi.org/10.1016/0007-0971(86)90062-8

[9] Mbata, G.C., Ajuonuma, B., Asodike, V.C. and Chukwumam, D. (2012) Tuberculosis of the Spine (Pott's Disease) Presenting as Hemiparesis. African Journal of Respiratory Medicine, 8, 18-20.

[10] Njoku, C.H., Makuside, M.A. and Ezunu, E.O. (2007) Experiences in Management of Pott's Paraplegia and Paraparesis in Medical Wards of Usmanu Danfodiyo University Teaching Hospital, Sokoto, Nigeria. Annals of African Medicine, 6, 22-25. https://doi.org/10.4103/1596-3519.55735

[11] Ogunsehinde, A.O., Obajimi, M.O., Ige, O.M., Alonge, T. and Fatunde, O.J. (2004) Computed Tomography Evaluation of TB Spine in Ibadan. West African Journal of Medicine, 23, 228-231. https://doi.org/10.4314/wajm.v23i3.28127

[12] Solagberu, B.A. and Ayorinde, R.O. (2001) Tuberculosis of the Spine in Illorin, Nigeria. East African Medical Journal, 78, 197-199.

https://doi.org/10.4314/eamj.v78i4.9062

[13] Talbot, J.C., Bismil, Q., Sarayala, D., Newton, D.A., Frizzel, R.M., et al. (2007) Musculoskeletal Tuberculosis in Bradford-A 6 Year Review. Annals of the Royal College of Surgeons of England, 89, 405-409. https://doi.org/10.1308/003588407X183328

[14] Ansari, S., Amamullah, F., Ahmad, K. and Raunijar, R.K. (2013) Pott's Spine. Diagnostic Imaging Modalities and Technology Advancements. North American Journal of Medical Sciences, 5, 404-411. https://doi.org/10.4103/1947-2714.115775

[15] Obisesan, A.A., Lagundoye, S.B. and Lawson, E.A. (1977) Radiological Features of Tuberculosis of the Spine in Ibadan, Nigeria. African Journal of Medicine and Medical Sciences, 6, 55-67.

[16] Desai, S.S. (1994) Early Diagnosis of Spinal TB by MRI. The Journal of Bone and Joint Surgery, 76, 863-869. https://doi.org/10.1302/0301-620X.76B6.7983108

[17] American Thoracic Society (2000) Diagnostic Standards and Classification of Tuberculosis in Adults and Children. American Journal of Respiratory and Critical Care Medicine, 161, 1376-1395. https://doi.org/10.1164/ajrccm.161.4.16141

[18] Dass, B., Puet, T.A. and Watanakunakorn, C. (2002) Tuberculosis of the Spine (Pott's Disease) Presenting as Compression Fractures. Spinal Cord, 40, 604-608. https://doi.org/10.1038/sj.sc.3101365

[19] Moon, M.S., Sung-Soo, K. and Hanlim, M. (2013) Tuberculosis of the Spine: Current Views in Diagnosis, Management, and Setting a Global Standard. Orthopaedics and Trauma, 27, 185-194. https://doi.org/10.1016/j.mporth.2013.03.001 